\title{
Electrodeposition and characterization of palladium nanostructures on stainless steel and application as hydrogen sensor
}

Hamid Heydari ${ }^{1}$, Abbas Abdolmaleki², Mohammad Bagher Gholivand ${ }^{1 *}$ and Hassan Shayani-jam³

${ }^{1}$ Department of Analytical Chemistry, Faculty of Chemistry, Razi University, Kermanshah

${ }^{2}$ Department of Chemistry, Malek Ashtar University of Technology, Tehran

${ }^{3}$ Department of Chemistry, Faculty of Science, University of Zanjan, Zanjan

E-Mail: mbgholivand@yahoo.com

\begin{abstract}
Palladium nanostructures have been deposited onto the stainless steel electrode by simple electrochemical deposition method in a buffer solution. The morphology of the synthesized Pd nanoparticles is controllable by deposition potentials because the driving force for various crystal growth mechanisms is merely dependent on applied potentials. The deposited Pd nanoparticles at higher applied potentials showed a cauliflower-like morphology with a nanoscale structure and large surface area. Then, an amperometric hydrogen sensor based on Pd nanoparticles can be constructed. This sensor is based on polymer electrolyte membrane fuel cell (PEMFC) and can be used at the ambient temperature. It is operated in the three-electrode mode that consists of three electrodes (working, counter and reference) and protonated Nafion membrane as proton conducting solid polymer electrolyte (SPE). The steady-state current response is obtained linearly to the concentrations of hydrogen from 50 to $2000 \mathrm{ppm}$, when a fixed potential of $0.2 \mathrm{~V}$ is applied to the sensor. Typical factors that influence the performance of the sensor are analyzed and discussed. The simple and inexpensive hydrogen sensor fabricated shows low LOD (10 ppm, based on $S / N=3)$, wide linear range (50-2000 ppm) and short response time (10-40 s).
\end{abstract}

Keywords: Electrodeposition, Palladium nanostructures, Cauliflower-like morphology, Amperometric hydrogen sensor, Stainless steel. 


\section{Introduction}

$\mathrm{I}$ $\mathrm{n}$ recent years, nanoparticles of noble metals have been the subject of numerous research investigations because of their potential applications as advanced materials with extraordinary physical and chemical properties [1-5].

The shape-controlled synthesis of metal nanoparticles has attracted significant interest because their properties and applications are affected greatly by their morphologies [6-10]. Noble-metal nanoparticles are of special interest for many applications, including catalysis [11-13] sensors [14] and other applications [13, 15].

Hydrogen, $\mathrm{H}_{2}$, is one of the most important industrial chemicals and is used in many chemical processes and various industries [1619]. In power plants, hydrogen is used for removing friction heat in turbines. It has also received much consideration recently in the search for renewable energy sources, particularly related to the development of fuel cells based on hydrogen fuel [20]. Hydrogen is found wide application as a fuel in rockets and as a lifting gas in weather balloons. Hydrogen as a fuel in futuristic automobiles using a $\mathrm{H}_{2} / \mathrm{O}_{2}$ fuel cell is a definite possibility, but there is a need for a hydrogen fuel leak-detection system [21]. Hydrogen is colorless, odorless, tasteless, flammable and explosive, so most human senses will not help to detect a leak. For these and other reasons, Hydrogen must be monitored. Therefore, substantial efforts are carried out to develop sensitive, reliable and inexpensive hydrogen sensors for the fast detection of hydrogen leaks [22-26]

Among the various noble metals nanoparticles, Pd nanoparticles has significant performance in the field of hydrogen storage and sensing [27-30]. Also, a simple method for synthesizing nanostructured $\mathrm{Pd}$ with controllable morphology remains a challenge.

Up to now, various methods have been developed to obtain the morphology controlled synthesis of Pd nanoparticles. Most of these methods are based on the solvothermal and hydrothermal processes, the use of surfactants, ligands or templates, solution-phase synthesis, chemical vapor deposition, chemical liquid deposition [25], microwave method [26], hydrogen reduction and electrochemical deposition [27-31].

Electrochemical deposition is superior to other methods morphology controlled synthesis because of the minimum requirement of the additives and absence of any interfering and byproducts generated during the electrodeposition of metal nanoparticles. Moreover, the nanoparticles can be synthesized in room temperature by electrodeposition. Hence, electrochemical deposition is a versatile technique that can be used to synthesize desirable nanostructures for diverse applications $[10,31-33]$. Under certain conditions, the morphology of electrodeposited metal nanoparticles can be controlled by regulating deposition potentials.

Herein, we report a low cost and simple method for the synthesis of $\mathrm{Pd}$ nanostructures with controllable morphology by electrochemical deposition. Also, this paper explains the configuration and fabrication of a new amperometric sensor of hydrogen. It uses a Nafion-117 membrane as a solid phase electrolyte and a polytetrafluoroethylene (PTFE) sheet as a gas-permeable diffusion membrane. This sensor was based on a three-electrode electrochemical cell system, employing palladium nanoparticles deposited on the stainless steel as a catalyst for the purpose of modification of electrodes. Two electrodes with large surface area are used as a working and a counter electrode. Another electrode (Pt/air) is used as a reference electrode. The fundamental principle, construction details and performance of the hydrogen sensor is discussed.

\section{Experimental}

\section{1- Electrochemical study and deposition}

All electrochemical measurements were performed at room temperature in a three- 
electrode configuration cell, with an $\mathrm{Ag} / \mathrm{AgCl}$ as the reference electrode. An Autolab (model PGSTAT302N) potentiostat/galvanostat was used to control the potential applied to the working electrode. The working electrode used in the voltammetry experiments and electrodeposition was a stainless steel mounted in Teflon with a specific area exposed to the solution. The potential of working electrode was measured against an $\mathrm{Ag} / \mathrm{AgCl}$ reference electrode and a platinum wire was used as the counter electrode.

All chemicals were reagent grade and were used without further purification.

\section{2- Characterizations}

The phase characterization of $\mathrm{Pd}$ nanoparticles was performed by means of X-ray diffraction (XRD) using a broker $\mathrm{d} 8$ advance $\mathrm{X}$ ray diffractometer with $\mathrm{Cu} \mathrm{K} \alpha$ radiation.

The morphology and crystalline size of the synthesized Pd samples were determined by using a Field emission scanning electron microscopy (Hitachi S4160 microscope).

\section{3- Materials preparation and sensor assembly}

The schematic diagram of the assembled sensor of hydrogen is shown in Figure 1. Commercial Nafion membrane from Dupont, USA (Nafion117) was used as proton conducting solid polymer electrolyte. The membrane was boiled in $5 \% \mathrm{H}_{2} \mathrm{O}_{2}$ for $1 \mathrm{~h}$ to remove organic impurities. After washing, the membrane was put in one molar Sulfuric acid at $100{ }^{\circ} \mathrm{C}$ for $2 \mathrm{~h}$ to remove inorganic impurities. After again washing with distilled water, the membrane was stored in distilled water.

Stainless steel mesh was used as the working electrodes on which the nanostructured Pd was deposited. Before electrochemical deposition, Stainless steel mesh was chemically cleaned with acetone using an ultrasonic agitator, followed by cleaning with distilled water. For electrodeposition of $\mathrm{Pd}$, a solution (ca. $200 \mathrm{~mL}$ ) of ammonia buffer $(\mathrm{pH} 10.0, \mathrm{c}=0.2 \mathrm{M})$ containing $1 \mathrm{mM}$ of $\mathrm{PdCl}_{2}$ was electrolyzed at $200 \mathrm{mV}$ versus $\mathrm{Ag} / \mathrm{AgCl}$, in an undivided cell. The electrolysis was terminated when the decay of the current became more than $95 \%$ of the initial current. At the end of electrolysis, the prepared electrode was taken out of the solution and rinsed with distilled water several times and then dried.

The sensor was prepared according to the following method. (i) The palladium deposited on stainless steel mesh (working electrode) was placed onto the PTFE membrane. (ii) The Nafion117 membrane was placed onto working electrode and the other side of the membrane was coated with a stainless steel mesh (counter electrode), a platinum (reference electrode) and an insulator of immediately. (iii) The assembly was placed in a hot-press at $110{ }^{\circ} \mathrm{C}$ and kept for $10 \mathrm{~min}$ under the pressure of $40 \mathrm{~kg} / \mathrm{cm}^{2}$ [34].

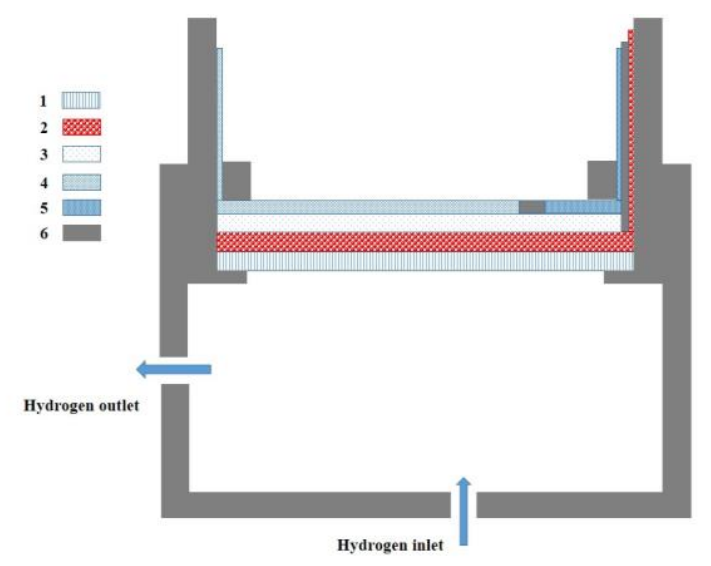

Figure 1: Schematic diagram of the hydrogen sensor structure. (1) PTFE membrane, (2) working electrode, (3) Nafion-117 membrane, (4) counter electrode, (5) reference electrode, (6) insulator (plexiglas).

\section{4- Sensor test}

Sensor testing was performed at ambient pressure and room temperature $\left(25 \pm 2{ }^{\circ} \mathrm{C}\right)$. High purity dry hydrogen and hydrogen-nitrogen gas mixtures were used for the measurements. The gas mixtures containing known concentration of hydrogen (in nitrogen) were passed to the sensing-electrode chamber at a $60 \mathrm{ml} / \mathrm{min}$ controlled flow rate by a flow meter (model Tucson/AZ, USA) (Figure 2). Before measurements, the sensing electrode was preconditioned by passing the humid carrier gases (nitrogen) until the output signals reached steady values. The relative humidity $(\mathrm{RH})$ of the gas was controlled, by passing them through a 
saturated solution of salt, to be $76 \%$. The measurements were performed using an electrochemical analyzer (Autolab model PGSTAT302N potentiostat/galvanostat) interfaced to a computer.

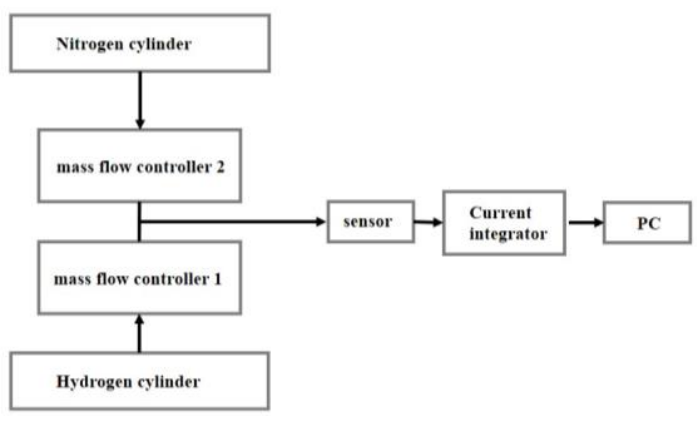

Figure 2: A block diagram of the experimental set-up for hydrogen measurement.

\section{Results and discussion}

\section{1- Electrochemical study}

The reduction of $\mathrm{Pd}$ was studied in some detail. Figure 3 shows cyclic voltammograms obtained for $\mathrm{pd}^{+2} 1 \mathrm{mM}$ in aqueous solution containing $0.2 \mathrm{M}$ ammonia buffer $(\mathrm{pH}=10.0)$.

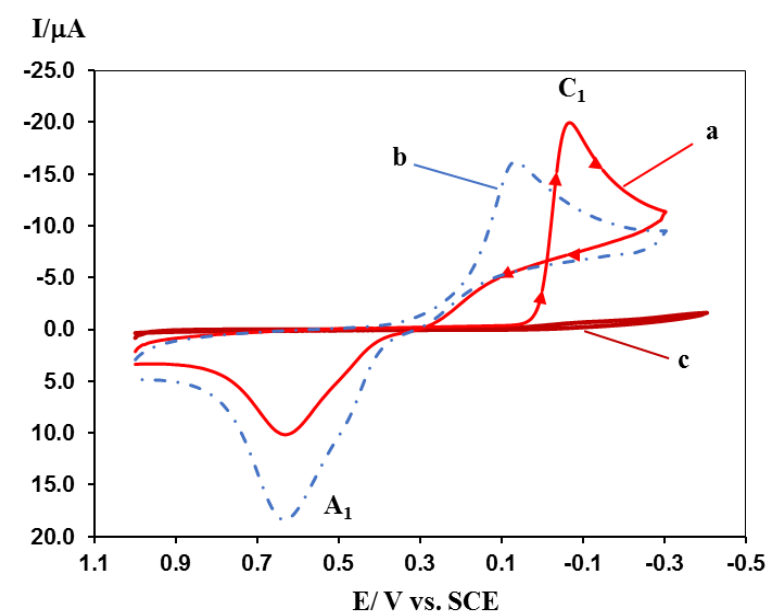

Figure 3: Cyclic voltammogram of $1 \mathrm{mM} \mathrm{PdCl} 2$ at stainless steel electrode for consecutive (a) first and (b) second cycle. In ammonia buffer solution ( $\mathrm{c}=0.2 \mathrm{M}, \mathrm{pH}=10.0$ ); (c) Cyclic voltammogram of stainless steel electrode in ammonia buffer solution. Scan rate: $10 \mathrm{mVs}^{-1} ; \mathrm{t}$ $=25^{\circ} \mathrm{C}$.

The cathodic current increases at potential more negative than $53.6 \mathrm{mV}$ vs. $\mathrm{Ag} / \mathrm{AgCl}$ in the more negative direction. The reduction peak $\left(\mathrm{C}_{1}\right)$ is observed at $-65.5 \mathrm{mV}$ and at more negative potential, current decrease by the Cottrell equation [35].

In the reverse sweep, current decreases and two crossovers are observed at $-11.9 \mathrm{mV}$ and 286 $\mathrm{mV}$ between the forward and reverse scans characteristic of metal deposition onto substrates of different nature.

After the direction of potential scan is switched at $-300 \mathrm{mV}$ to a positive scan, $\mathrm{Pd}$ already deposited on the electrode surface continues to grow because of the deposition reaction remaining thermodynamically and kinetically favorable. In the following anodic potential sweep, at more positive potential, one broad anodic peak is observed at $0.631 \mathrm{mV}$ which is attributed to the stripping (oxidation) of $\mathrm{Pd}$ deposited during the scan in cathodic direction. The distance and relative position of the cathodic and anodic peaks confirm the current-potential behavior of an irreversible system [36-38].

During the second cycle, lower crystallization overpotential is required for palladium electrodeposition (Fig3. Curve b). This phenomenon demonstrates that residual $\mathrm{Pd}$ deposit in the first cycle would allow easier deposition of $\mathrm{Pd}$ in the second cathodic cycle. Also, both the cathodic onset and peak potentials shift to the $482 \mathrm{mV}$ and $71.4 \mathrm{mV}$, respectively. Whereas, these potentials do not change during the potential scan in anodic direction in the second cycle (Fig3. Curve b). Thus, higher required overpotential during first scan arises from the nucleation of $\mathrm{Pd}$ on the bare stainless steel electrode. In other words, the deposition of $\mathrm{Pd}$ (II) on Pd, in the second scan, is kinetically and thermodynamically favourable than the deposition of Pd (II) on stainless steel in first scan. As a result, $\mathrm{Pd}$ deposits on stainless steel by forming nuclei followed by the three dimensional growth based on the Volmer growth mechanism [39].

\section{2- Electrochemical deposition of Pd nanostructures}

Figure 4 shows SEM photographs of the deposited Pd. As shown in, at the depositing potential of $-200 \mathrm{mV}$ vs. $\mathrm{Ag} / \mathrm{AgCl}$, the deposited $\mathrm{Pd}$ shows nanostructures configuration having a 
cauliflower shape with particle sizes ranging from $50 \mathrm{~nm}$ to several hundreds of nanometres. Each particle of such structure is further covered by smaller particles of similar shape (Figure $4 b$, inside the circle). The smallest particles on the surface layer may be in the nanometres range. This rough and porous nanostructures increases the active surface area of the electrode when compared to an electrode with a smooth surface having the same geometric shape.

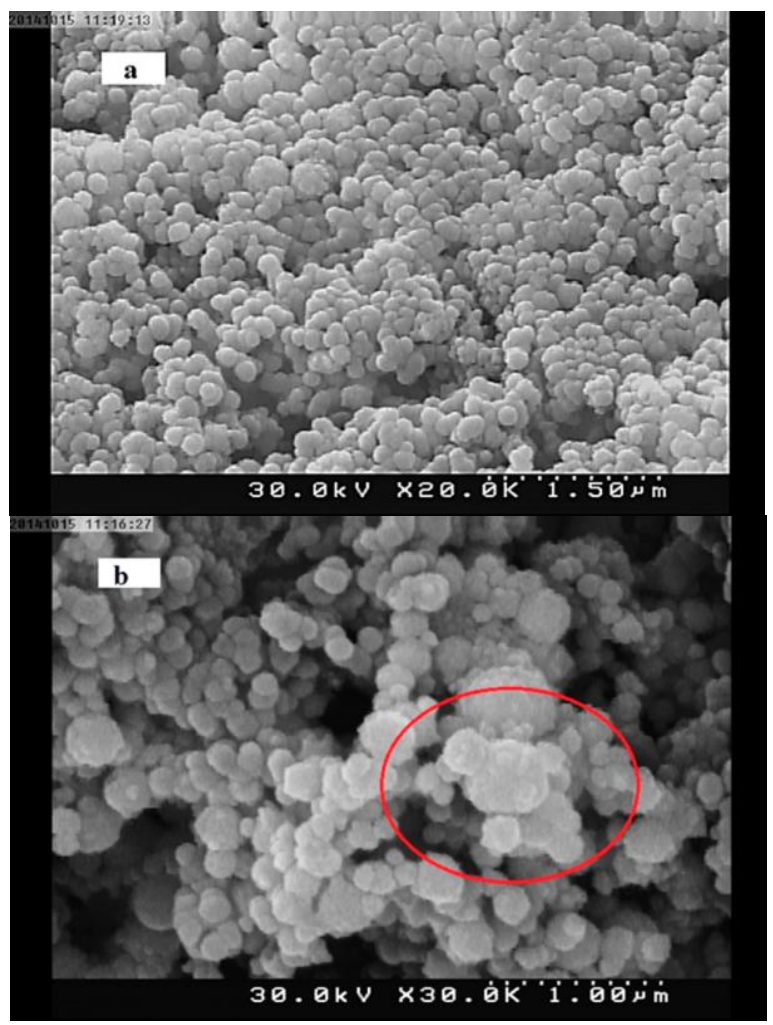

Figure 4: FESEM image of the cauliflower-like Pd nanoparticles.

The XRD pattern (Figure 5) confirms that the cauliflower-like deposited Pd is only composed of Pd and other peaks, such as Pd oxide, cannot be detected, confirming the high purity of the obtained product. The diffraction peaks in the range of $20<2 \theta<90^{\circ}$ can be indexed as fcc structures Pd (111), (200), (220), and (311), all of which are in good accordance with the ASTM standard 05-0681.

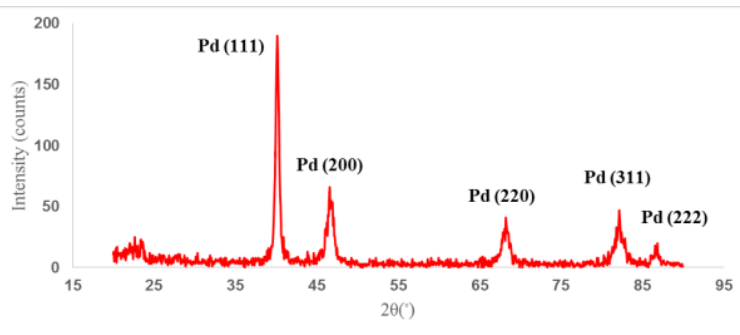

Figure 5: XRD pattern of the deposited cauliflower-like Pd nanoparticles.

\section{3- Controlling the morphology of deposited Pd nanoparticles}

Further studies indicate that the morphology of electrodeposited nanoparticles of $\mathrm{Pd}$ can be simply controlled by regulating the deposition potential. Figure 6 shows SEM micrographs of the deposited products. At the deposition potential of $-200 \mathrm{mV}$ (Figure $6 \mathrm{c}$ and $\mathrm{d}$ ), the deposited Pd nanoparticles show a cauliflowerlike morphology. At the deposition potential of 0.0 (Figure 6a) and $53.6 \mathrm{mV}$ (Figure 6b), the obtained Pd products have smooth and flat morphology.

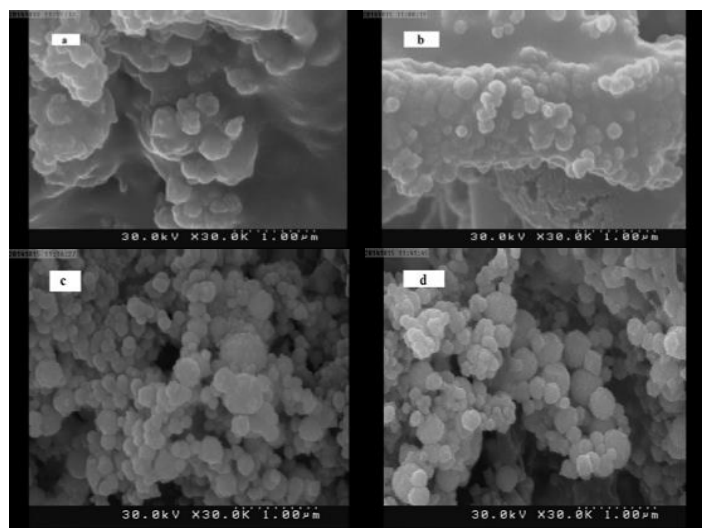

Figure 6: FESEM image of the Pd particles in crystallization overpotential (a) 0.0, (b) 53.6, (c) and (d) $-200 \mathrm{mV}$ vs. $\mathrm{Ag} / \mathrm{AgCl}$.

\section{4- Deposition mechanism}

Electrochemical deposition process of $\mathrm{Pd}$ nanoparticles includes the nucleation and growth of crystals. It is generally believed that electrochemical nucleation of a metal crystal on the different substrate is accomplished on the high-energy surface sites such as edges, corners, and other surface defects [40-42].Generally, it can be said that the morphology of crystals strongly depends on the "thermodynamic distance" 
between the real conditions of crystallization and the thermodynamic equilibrium [43, 44]. It has been reported that the fractal structures are formed at extremely non equilibrium conditions, and the growth of such patterns occur through diffusion-limited aggregation (DLA) or dense branching morphologies (DBM) [45]. This 'distance' in electrochemical deposition can be easily controlled by the applied potential if other depositing conditions, such as the type and concentration of electrolyte and temperature are fixed. At high applied potential $(-200 \mathrm{mV}$ vs. $\mathrm{Ag} / \mathrm{AgCl}$ ), the 'distance' is significant and the $\mathrm{Pd}$ nanoparticles is deposited far away from thermodynamic equilibrium. As a result, according to the lowest-energy principle, higher overvoltage leading to the formation of cauliflower-like nanostructures [46-48].

Under a lower applied potential (53.6 and $0.00 \mathrm{mV}$ vs. $\mathrm{Ag} / \mathrm{AgCl}$ ), the 'distance' is not so large and the Pd particles are deposited closer to the thermodynamic equilibrium. Under these conditions, the mechanism of crystal growth changes and conversion of rough cauliflowerlike morphology to smooth morphology occurs.

\section{5- Application of Pd cauliflower - like nanostructures}

Pd cauliflower-like nanoparticles can be easily electrodeposited on the surface of stainless steel electrode. From a technical point of view, the obtained cauliflower-like $\mathrm{Pd}$ nanoparticles may have extensive applications in various fields of electrochemistry. In the recent years, considerations in the research and progress of noble metal nanoparticles have increasingly emphasized the application in various substrates sensing. The detection of $\mathrm{H}_{2}$ has become very important because of its wide and varied applications. Therefore, amperometric hydrogen sensor based on cauliflower-like Pd nanostructures could be built. In all amperometric gas sensors, determination is done by measuring the current in the electrochemical cell between the working and counter electrode over the time as a function of the analyte concentration.

\subsection{1- Principles of the amperometric hydrogen sensor}

Amperometric sensor components were assembled and fixed by Plexiglas according to Figure 1. The sensing performance of the constructed amperometric sensor was investigated in order to the detection of hydrogen in nitrogen. The following electrochemical redox reactions take place at the electrodes, i.e. oxidation at the anode and reduction at the cathode.

$$
\mathrm{H}_{2} \longrightarrow 2 \mathrm{H}^{+}+2 e^{-}(1), \quad 1 / 2 \mathrm{O}_{2}+2 \mathrm{H}^{+}+2 e^{-} \longrightarrow \mathrm{H}_{2} \mathrm{O}(2)
$$

In this cell, reaction (1) occurs at the sensing electrode and reaction (2) occurs at the counter electrode. Pt/air is used as a reference electrode for the above mentioned electrochemical cell. Meanwhile, the protons (Anodic reaction product) move toward the counter electrode through the Nafion membrane (proton conducting solid polymer electrolyte).

Under potentiostatic condition, the sensor response current is controlled by the diffusion rate of hydrogen to the sensing electrode or the oxidation rate of hydrogen at the working electrode surface. When the diffusion rate of hydrogen toward sensing electrode is much lower than the oxidation rate of hydrogen, the electrochemical reactions are a diffusion-limited process. Therefore, the steady-state current responses were observed in constant concentration of hydrogen when the constant potential of $0.2 \mathrm{~V}$ was applied on the sensor. The use of The PTFE membrane, as a gas-permeable diffusion membrane, provide diffusion controlled process. Under this condition, we can write: $I_{l}=K C_{b}$ (3) Where $\mathrm{Cb}$ and $\mathrm{K}$ are the concentration of hydrogen and the sensitivity of the sensor, respectively. If $K$ is a constant, the limiting current $\mathrm{I}$ is proportional to the concentration of hydrogen.

\subsection{2- Measurements of the sensor}

Limiting current of the sensor depends on several factors such as the diffusion coefficient of hydrogen, gas-diffusion barrier and flow rate of test gas. Because of the electrochemical reactions that occur in the cell are a diffusion-limited, diffusion rate of hydrogen and the resulting response signal is influenced by flow rate of test gas. Figure 7 shows output current versus the 
gas flow rate for the sensor in the presence of hydrogen (500 ppm). As it is clear from the plot, the current response increase quickly before the flow rates reach $50 \mathrm{ml} / \mathrm{min}$, then they increase slowly and achieve nearly a plateau state at 60-80 $\mathrm{ml} / \mathrm{min}$. In the present work, all sensor measurements were performed at flow rate of 60 $\mathrm{ml} / \mathrm{min}$.

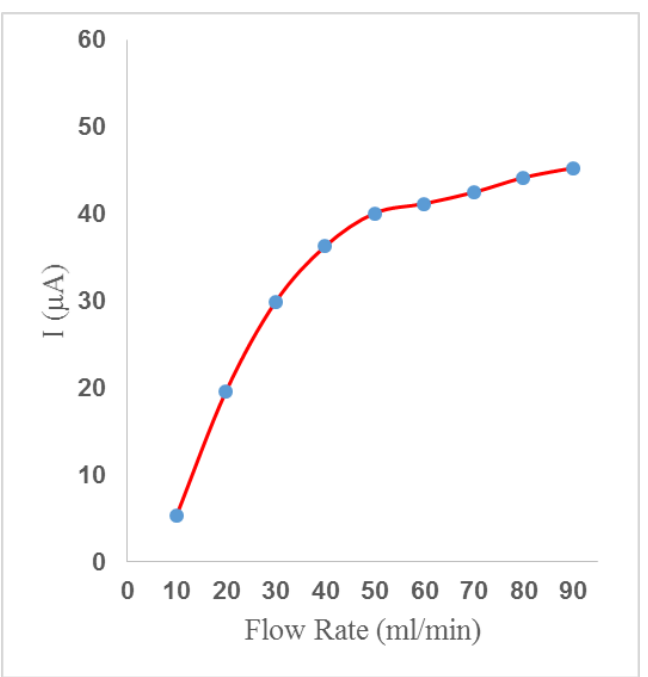

Figure 7: The plot of response signal vs. $\mathrm{H}_{2}$ gas flow rate for the sensor in the presence of 500 ppm hydrogen.

Another important factor that affects the response of the sensor is the relative humidity of the test gas mixture. Since the protonconductivity of the Nafion-117 membrane strongly depends on the water content of the membrane, it is necessary to keep the relative humidity $(\mathrm{RH})$ of test gas mixture constant. Therefore, sensor was tested in various relative humidity $(\mathrm{RH})$ of test gas. Table 1 shows the sensitivities of the sensor at $\mathrm{RH} 42 \%$ (saturated $\mathrm{Zn}(\mathrm{NO} 3)_{2}$ solution), $76 \%$ (saturated $\mathrm{NaH}_{2} \mathrm{PO}_{4}$ solution) [34] in the range of 50-2000 ppm hydrogen concentration. The results showed that the relative humidity of the test gas mixture has a strong effect on the sensitivity of the sensor.

Table 1. The sensitivities of sensor at various relative humidities

\begin{tabular}{cc}
\hline Relative humidity $(\%)$ & Sensitivity $(\mu \mathrm{A} / \mathrm{ppm})$ \\
\hline 42 & 0.051 \\
76 & 0.079 \\
\hline
\end{tabular}

Figure 8 shows typical responses of the sensor to the step change of hydrogen concentration in nitrogen (50-2000 ppm) at room temperature. Prior to the introduction a new concentration of hydrogen, the sensor was imposed with nitrogen, to bring current back to the baseline level. Figure 8 shows that the sensor response is rapid for hydrogen concentrations between 50-2000 ppm. At a step change in the hydrogen concentration, the response time is typically $10-40 \mathrm{~s}$ to achieve a signal level of $90 \%$ of the steady-state current.

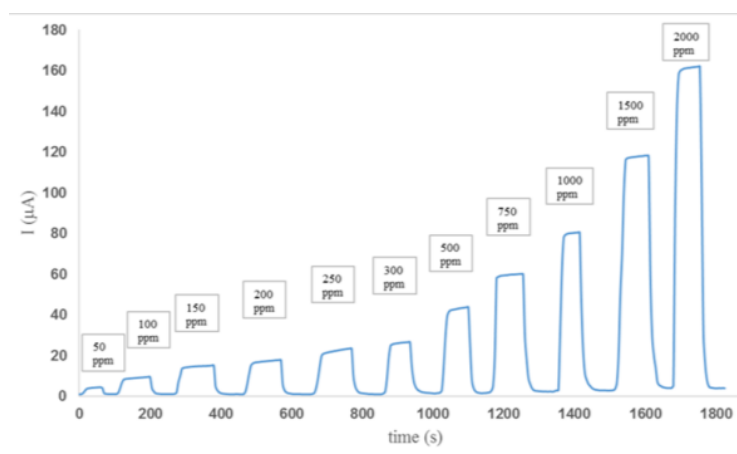

Figure 8: Response curves of the sensor for various concentrations of hydrogen.

The long-term stability of the sensor for different concentrations of hydrogen is shown in Figure 9. As can be seen, the sensor has good reproducibility and long-term stability. The performance of the sensor during a period of 4 months was very steady.

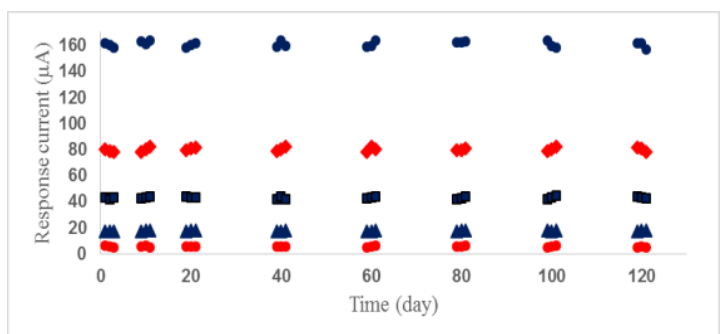

Figure 9: The long-term performance of the sensor for different concentrations of hydrogen.

A plot of the maximum output current of the sensor against the hydrogen gas concentration is linear as shown in Figure 10. According to Figure 10, the linear regression equation is $\mathrm{y}=$ $1.66+0.0791 \times(50-2000 \mathrm{ppm})$ and $\mathrm{y}=0.64+$ $0.0855 x(50-500 \mathrm{ppm})$ for hydrogen concentration range. Where $y$ and $x$ are the response current $(\mu \mathrm{A})$ of the sensor and the concentrations (ppm) of hydrogen, respectively. The LOD (10 ppm, based on $\mathrm{S} / \mathrm{N}=3)$, upper range (2000 ppm) and 
sensitivity $(0.0791 \mu \mathrm{A} / \mathrm{ppm})$ of the sensor were improved compared with the previously reported amperometric sensor (table 2).

Table 2. Example of electrochemical $\mathrm{H}_{2}$ sensors

\begin{tabular}{ccccc}
\hline gas & electrolyte & $\begin{array}{c}\text { LOD } \\
{\left[\mathrm{H}_{2}\right]}\end{array}$ & $\begin{array}{c}\text { upper } \\
\text { range }\end{array}$ & ref \\
\hline $\mathrm{H}_{2}$-air & Nafion & $10 \mathrm{ppm}$ & $1000 \mathrm{ppm}$ & {$[48]$} \\
$\mathrm{H}_{2}-\mathrm{N}_{2}-$ & $\begin{array}{c}\text { proton- } \\
\text { conducting } \\
\mathrm{H}_{2} \mathrm{O}\end{array}$ & $0.5 \%$ & $2 \%$ & {$[49]$} \\
& $\begin{array}{c}\text { solid } \\
\text { electrolytes }\end{array}$ & & \\
$\mathrm{H}_{2}$-air & Nafion & $200 \mathrm{ppm}$ & $12000 \mathrm{ppm}$ & {$[34]$} \\
$\mathrm{H}_{2}-\mathrm{N}_{2}$ & $1 \mathrm{M} \mathrm{H}_{2} \mathrm{SO}_{4}$ & $5 \mathrm{ppm}$ & $1000 \mathrm{ppm}$ & {$[50]$} \\
$\mathrm{H}_{2}-\mathrm{N}_{2}$ & Nafion & $10 \mathrm{ppm}$ & $2000 \mathrm{ppm}$ & This work \\
\hline \multicolumn{5}{c}{} \\
\hline
\end{tabular}

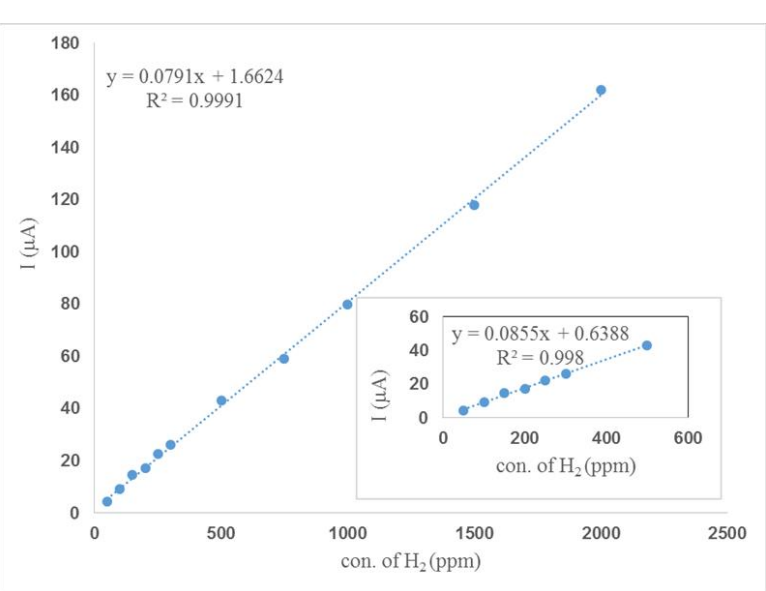

Figure 10: The calibration plot of steadycurrents vs. concentrations of hydrogen.

In this sensor, the catalyst of Pd supported on stainless steel has high catalysis performance. The presence of PTFE membrane as a gaspermeable diffusion membrane ensures that electrochemical reactions are a diffusion-limited process. Based on our experimental attempts, in the range of 50-2000 ppm, the sensitivity of the sensor is stable, which implies that the water content in the Nafion-117 as a solid phase electrolyte is relatively steady.

The results that obtained with hydrogen in air (50-2000 ppm range) are the same as that in nitrogen. This sensor can be used for determination of hydrogen concentration in air at the ambient temperature. Also, because the PTFE membrane as a gas-permeable diffusion membrane is hydrophobic, determination of the dissolved hydrogen in aqueous solution is possible by immerging the working electrode in the aqueous solution and exposing the counter and the reference electrode to air.

\section{Conclusions}

Electrodeposition of palladium is carried out on a stainless steel electrode in buffer solution with various deposition mechanisms which can be particularly controlled by the deposition potential. The deposited Pd nanoparticles display cauliflower-like morphology when higher overpotentials are applied on the working electrode. The obtained Pd nanoparticles can be used to prepare electrodes with large surface area in amperometric hydrogen sensor. This large surface provides more reaction sites between $\mathrm{Pd}$ nanoparticles and hydrogen to increase sensitivity and reduce response time of the sensor. Furthermore, the construction of a practically applicable amperometric hydrogen sensor was demonstrated based on polymer electrolyte membrane fuel cell (PEMFC) consists of three electrodes (working, counter and reference), protonated Nafion membrane as proton conducting solid polymer electrolyte (SPE) and a polytetrafluoroethylene (PTFE) sheet as a gas-permeable diffusion membrane.

The prepared sensor of hydrogen has shown good performance including high sensitivity, short response and recovery time. Also, it showed a stable and linear response to hydrogen gas in the 50 to 2000 ppm range. The sensor can be used to determination of hydrogen concentration in air at the ambient temperature. Also, the special structure of the sensor can be used as a pattern to make a sensor that be able to determine hydrogen concentration in aqueous solution at the ambient temperature.

\section{Acknowledgment}

The authors gratefully acknowledge the financial support of this work by the Research centers of Razi University and University of Zanjan.

\section{References}

[1] Wang, F., Lai, Y., Zhao, B., Hu, X., Zhang, D., Hua, K. (2010). Tunable growth of nanodendritic silver by galvanic-cell mechanism on formed activated carbon. Chem. Commun., 46, 3782-3784.

[2] Lee, K., Savadogo, O., Ishihara, A., Mitsushima, S., Kamiya, N., Ota, K-I., (2006). 
Methanol-tolerant oxygen reduction electrocatalysts based on Pd-3D transition metal alloys for direct methanol fuel cells batteries, fuel cells, and energy conversion. J. Eletrochem. Soc., 153, A20-A24.

[3] Savadogo, O., Lee, K., Oishi, K., Mitsushima, S., Kamiya, N., Ota, K-I., (2004). New palladium alloys catalyst for the oxygen reduction reaction in an acid medium. Electrochem. Commun., 6, 105-109.

[4] Nie, G., Lu, X., Lei, J., Yang, L., Bian, X., Tong, Y., Wang, C. (2013). Sacrificial templateassisted fabrication of palladium hollow nanocubes and their application in electrochemical detection toward hydrogen peroxide. Electrochim. Acta, 99, 145-151.

[5] Shao, M-H., Sasaki, K., Adzic, R. R., (2006). Pd-Fe Nanoparticles as electrocatalysts for oxygen reduction. J. Am. Chem. Soc., 128, 3526-3527.

[6] Song, H. M., Anjumb, D. H., Khashab, N. M., (2012). Shape-controlled synthesis of Au@Pd core-shell nanoparticles and their corresponding electrochemical properties. RSC Adv., 2, 36213624.

[7] Sau, T. K., Murphy, C. J., (2004). Room temperature, high-yield synthesis of multiple shapes of gold nanoparticles in aqueous solution. J. Am. Chem. Soc., 126, 8648-8649.

[8] Jin, R., Cao, Y., Mirkin, C. A., Kelly, K. L., Schatz, G. C., Zheng, J. G., (2001). Photoinduced conversion of silver nanospheres to nanoprisms. Science, 294, 1901-1903.

[9] Niu, X., Zhao, H., Lan M., Zhou, L., (2015). Platinum nanoparticles encapsulated in carbon microspheres: toward electro-catalyzing glucose with high activity and stability. Electrochim. Acta, 151, 326-331.

[10] Xu, S., Zhang, H., Huang, F., Wang, P., Xia, Y., Li Z., Huang, W., (2013). Electrochemical fabrication of a cauliflower-like nanostructured $\mathrm{Pd}$ film from pure $\mathrm{Pd}$ and its applications in electrocatalysis and electroanalysis. Electrochim. Acta, 107, 537-541.

[11] Brugger, P. A., Cuendet, P., Gratzel, M., (1981). Ultrafine and specific catalysts affording efficient hydrogen evolution from water under visible light illumination. J. Am. Chem. Soc., 103, 2923-2927.

[12] Wen, S. H., Cui, S. G., Shi, L., Liang, R. P., Qiu, J. D., (2015). Decoration of carbon nanotubes with highly dispersed platinum nanoparticles for electrocatalytic application. Journal of Electroanalytical Chemistry, 738, 7783.

[13] Chen, C. W., Serizawa, T., Akashi, M., (1999). Preparation of platinum colloids on polystyrene nanospheres and their catalytic properties in hydrogenation. Chem. Mater., 11, 1381-1389.

[14] Matko, I., Gaidi, M., Hazemann, J. L., Chenevier, B., Labeau, M., (1999). Electrical properties under polluting gas (CO) of $\mathrm{Pt}$ - and Pd-doped polycrystalline $\mathrm{SnO}_{2}$ thin films: analysis of the metal aggregate size effect. Sensors and Actuators B, 59, 210-215.

[15] Wu, L., Zhang, X., Chen, J., (2014). A new third-generation biosensor for superoxide anion based on dendritic gold nanostructure. Journal of Electroanalytical Chemistry, 726, 112118.

[16] Linden, D., (1984). Hand-book of fuel cell and batteries, MacGraw-Hill, New York.

[17] Hunter, G. W., (1992). A survey and analysis of commercially available hydrogen sensors, NASA Technical Memorandum, 105878.

[18] Hunter, G. W., Makel, D. B., Jansa, E. D., Patterson, G., Cova, P. J., Liu, C. C., Wu, Q. H., Powers, W. T., (1995). A hydrogen leak detection system for aerospace and commercial applications, NASA Technical Memorandum, 1070363.

[19] Weiller, B. H., Barrie, J. D., Aitchison, K. A., Chaffee, P. D., (1994). Chemical microsensors for satellite applications. Mater. Res. Soc. Symp. Proc., 360, 535.

[20] Amason, B., Sigfusson, T. I., (2000). Iceland - a future hydrogen economy. Int. J. Hydrogen Energy, 25, 389-394.

[21] Linden, D., (1995). Handbook of fuel cells and batteries, McGraw-Hill, New York.

[22] Duana, B. K., Bohn, P. W., (2010). High sensitivity hydrogen sensing with Pt-decorated porous gallium nitride prepared by metalassisted electroless etching. Analyst, 135, 902907.

[23] Opekar, F., Langmaier, J., Samec, Z., (1994). Indicator, reference platinum/solid polymer electrolyte electrodes for a simple solidstate amperometric hydrogen sensor. Journal of Electroanalytical Chemistry, 379, 301-306.

[24] Bevenot, X., Trouillet, A., Veillas, C., Gagnarie, H., Clement, M., (2000). Hydrogen leak detection using an optical fibre sensor for 
aerospace applications. Sensors and Actuators B, 67, 57-67.

[25] Matsumiya, M., Shin, W., Izu, N., Murayama, N., (2003). Nano-structured thin-film $\mathrm{Pt}$ catalyst for thermoelectric hydrogen gas sensor. Sensors and Actuators B, 93, 309-315.

[26] Han, C. H., Han, S. D., Singh, I., Toupance, T., (2005). Micro-bead of nanocrystalline F-doped $\mathrm{SnO}_{2}$ as a sensitive hydrogen gas sensor. Sensors and Actuators B, 109, 264269.

[27] Lewis, F. A., (1982). The palladiumhydrogen system. Platinum Metals Rev., 26, 2027.

[28] Christofides C., Mandelis, A., (1990). Solid-state sensors for trace hydrogen gas detection. J. Appl. Phys., 68, R1-R30.

[29] Mortazavi, S. Z., Parvin, P., Reyhani, A., Malekfar, R., Mirershadid, S., (2013). Hydrogen storage property of laser induced Pdnanoparticle decorated multi-walled carbon nanotubes. RSC Advances, 3, 1397-1409.

[30] Ding, D., Chen, Z., (2007). A pyrolytic, carbon-stabilized, nanoporous Pd film for widerange $\mathrm{H}_{2}$ sensing. Adv. Mater., 19, 1996-1999.

[31] Bhushan, B., (2004). Handbook of nanotechnology, Springer, Berlin, p 100.

[32] Jia, F., Wong, K., Du, R., (2009). Direct growth of highly catalytic palladium nanoplates array onto gold substrate by a template-free electrochemical route. Electrochem. Commun., 11, 519-521.

[33] Jia, F., Wong, K., Zhang, L., (2009). Electrochemical synthesis of nanostructured palladium of different morphology directly on gold substrate through a cyclic deposition/dissolution route. J. Phys. Chem. C, 113, 7200-7206.

[34] Lu, X., Wu, S., Wang, L., Su, Z., (2005). Solid-state amperometric hydrogen sensor based on polymer electrolyte membrane fuel cell. Sensor and Actuators B, 107, 812-817.

[35] Bard, A. J., Faulkner, L. R., (2001). Electrochemical methods; fundamentals and applications, Wiley, New York.

[36] Fletcher, S., (1983). Some new formulae applicable to electrochemical nucleation/growth/collision. Electrochim. Acta, 28, 917-923.

[37] Fletcher, S., Halliday, C. S., Gates, D., Westcott, M., win, T. L, Nelson, G., (1983). The response of some nucleation/growth processes to triangular scans of potential. Journal of Electroanalytical Chemistry, 159, 267-285.

[38] Danaee, I., (2013). Theoretical and experimental studies of layer by layer nucleation and growth of palladium on stainless steel 316L. chemija., 24, 128-136.

[39] Pötzschke, R. T., Gervasi, C. A., Vinzelberg, S., Staikov, G., Lorenz, W. J., (1995). Nanoscale studies of Ag electrodeposition on HOPG (0001). Electrochim. Acta, 40, 1469-1474.

[40] Oskam, G., Long, J. G., Natarajan, A., Searson, P. C., (1998). Electrochemical deposition of metals onto silicon. J. Phys. D: Appl. Phys., 31, 1927-1949.

[41] Velmurugan, J., Noel, J. M., Nogala, W., Mirkin, M. V., (2012). Nucleation and growth of metal on nanoelectrodes. Chem. Sci., 3, 33073314.

[42] Velmurugan, J., Noel, J. M., Mirkin, M. V., (2014). Nucleation and growth of mercury on Pt nanoelectrodes at different overpotentials. Chem. Sci., 5, 189-194.

[43] Kuroda, T., Irisawa, T., Ookawa, A., (1977). Growth of a polyhedral crystal from solution and its morphological stability. J. Cryst. Growth., 42, 41-46.

[44] Oaki, Y., Imai, H., (2003). Experimental demonstration for the morphological evolution of crystals grown in gel media. Cryst. Growth. Des., 3, 711-716.

[45] Fukami, K., Nakanishi, S., Yamasaki, H., Tada, T., Sonoda, K., Kamikawa, N., Tsuji, N., Sakaguchi, H., Nakato, Y., (2007). General mechanism for the synchronization of electrochemicaloscillations and self-organized dendrite electrodeposition of metals with ordered 2D and3D microstructures. J. Phys. Chem. C, 111, 1150-1160.

[46] Yu, J., Fujita, T., Inoue, A., Sakurai, T., Chen, M., (2010). Electrochemical synthesis of palladium nanostructures with controllable morphology. Nanotechnology, 21, 085601-7.

[47] Corduneanu, O., Diculescu, V. C., Chiorcea-Paquim, A. M., Oliveira-Brett, A. M., (2008). Shape-controlled palladium nanowires and nanoparticles electrodeposited on carbon electrodes. Journal of Electroanalytical Chemistry, 624, 97-108.

[48] Sakthivel, M., Weppner, W., (2007). Electrode kinetics of amperometric hydrogen sensors for hydrogen detection at low parts per 
million level. J. Solid State Electrochem., 11, 561570.

[49] Kalyakin, A., Fadeyev, G., Demin, F. A., Gorbova, E., Brouzgou, A., Volkov, A., Tsiakaras, P., (2014). Application of Solid oxide protonconducting electrolytes for amperometric analysis of hydrogen in $\mathrm{H}_{2}+\mathrm{N}_{2}+\mathrm{H}_{2} \mathrm{O}$ gas mixtures, Electrochim. Acta, 141, 120-125.

[50] Rashida, M., Junb, T. S., Jungc, Y., Kima, Y. S., (2015). Bimetallic core-shell Ag@Pt nanoparticle-decorated MWNTelectrodes for amperometric $\mathrm{H}_{2}$ sensors and direct methanol fuel cells. Sensors and Actuators B, 208, 7-13. 